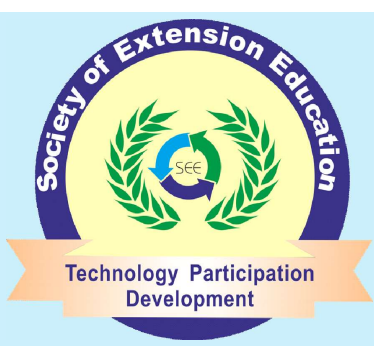

Research Article

\section{Indian Research Journal of Extension Education}

ISSN: 0972-2181 (Print), 0976-1071 (Online)

NAAS Rating : 5.22

Journal homepage: seea.org.in

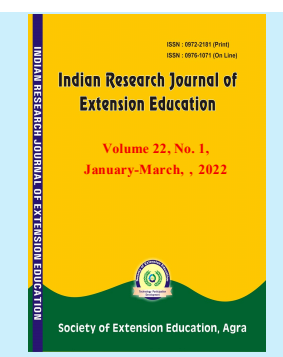

https://doi.org/10.54986/irjee/2022/jan_mar/38-43

\title{
Knowledge of the Farmers about Water Management Practices in Upper Krishna Command Area of Karnataka
}

\author{
Navinkumar ${ }^{1}$, S.B. Goudappa ${ }^{2}$, Shivanand Kammar ${ }^{3}$, \\ D.M. Chandargi ${ }^{4}$, Suresh S. Patil ${ }^{5}$ and B.M. Dodamani ${ }^{6}$
}

1.Ph. D Scholar (Agril. Ext.), 2. Prof. and Head (Agril. Ext.), 3. Asst. Prof. (Agril. Ext.), 4. Prof. and DE (Agril. Ext.), 5. Dean (Agri.) and 6. Prof and Head (Agronomy), UAS, Raichur. Corresponding author e-mail : navinkumar1323@gmail.com

Paper Received on September 21, 2021, Accepted on Novembe 22, 2021 and Published Online on January 01, 2022

\begin{abstract}
The present study was conducted during the year 2018-20 in Upper Krishna command area to ascertain the knowledge of the farmers towards water management practices. The study was conducted in Vijayapura, Yadgir and Raichur districts of UKP Command Area. Two talukas from each district were selected based on highest irrigated area by UKP project. The talukas selected for the study were Sindagi and Indi from Vijayapura district, Surpur and Shahapur from Yadgir district and Deodurga and Lingasugur from Raichur district, respectively. From each taluks four villages had selected and from each selected villages ten samples had randomly selected. Thus, total sample size was 240. With respect to overall knowledge of the farmers about selected water management practices in command area, more than half (51.67\%) of the farmers had high knowledge level about water management practices, followed by medium (30.00\%) and low (18.33\%).
\end{abstract}

Key words: Command area; Water management; Knowledgep; Channel and distributaries.

In India, more than 70 per cent of the annual rainfall occurs during the South West monsoon period from June to September. Irrigation especially during winter months enable increased intensity of land use for cultivation. The irrigated agriculture must expand considerably in order to increase the food production to the required level. Hence, the management of available irrigation water assumes greater significance. But water management is not a new concept to our country. Chanakya in his Arthashashtra has urged the rulers to assist farmers in the construction of irrigation works and to give them various incentives. Karikalan, the Chola king, built an anicut across river Cauvery, which is standing still for over 1600 years (Chinnadurai et al.,
2013). The river Krishna is the second biggest river in peninsular India. It rises in Mahabaleshwar of Maharastra at an altitude of $1,338 \mathrm{~m}$. above mean sea level (MSL). It flows from west to east for a length of about $1392 \mathrm{~km}$. through states of Maharastra, Karnataka, Telangana and Andra Pradesh, and finally merges in Bay of Bengal. In upper reaches, the river passes through hilly terrain receiving high rainfall varying from $3800 \mathrm{~mm}$. to $6350 \mathrm{~mm}$., but however in lower reaches it runs over a plain area where rainfall dwindles down to about $500 \mathrm{~mm}$. The catchment of river covers a total area of about $2,57,000 \mathrm{sq}$. km., of which 68,800 sq. km. $(26.80 \%)$ lies in the state of Maharastra, $1,12,600$ sq.km. (43.80\%) in Karnataka and 75,600 
sq.km. (29.40\%) in Andra Pradesh (Anon., 1996).

Water Management is important since it helps determine future irrigation expectations. Drip irrigation system was observed in terms of increase in water saving from 26 to 50 per cent, saving in expenditure on purchase of fertilizer, plant protection chemicals, saving in weed control expenses. There is saving in labour utilization as well as electricity charges between the range of Rs. 1001 to 5000 (Shaik and Khandave., 2019). Water management is the management of water resources under set of policies and regulations. Sashilila and Patra (2018) proves that the beneficiaries have achieved significant improvement in social, physical, economic and gender aspects of social inclusion $(Z$ value of -9.0157, Z-critical of 1.96 and $p$ value of 0.001 ) after the implementation of the project and that the IWMP has addressed the equity issues quite effectively. The programme has ensured a positive effect in creating a socially inclusive society for the beneficiaries. Also, majority of the beneficiaries i.e., 63 per cent had moderately benefitted in terms of social inclusion from the implementation of Integrated Watershed Management Project. On the other hand, a considerable number of beneficiaries $(23.00 \%)$ are greatly benefitted from IWMP. Water, once an abundant natural resource, is becoming a more valuable commodity due to droughts on one side and overuse on the other. Hence, the knowledge of the farmers about water management practices in command area had been assessed.

\section{METHODOLOGY}

The present study was conducted during the year 2019-20 in Upper Krishna command area to ascertain the knowledge of the farmers towards water management practices. The Ex-post-facto-research design was used for the study. The study was conducted in Vijayapura, Yadgir and Raichur districts of UKP Command Area. Two talukas from each district were selected by using purposive sampling technique based on highest irrigated area by UKP project. In selection of villages, same criteria of highest area under irrigation by UKP project was followed in consultation with officials of Command Area Development Authority. Thus, a total of 24 villages were selected from six taluks. From each selected village, the farmers who are beneficiary of UKP project were considered as sample for the study. Keeping this in mind ten sample farmers had selected randomly from each of the selected villages. Thus, total sample size was 240 .

Each practice was put in the question form to obtain response from the respondents, the correct response was given a score of one and incorrect response was given a score of zero. The maximum scores that a respondent could obtain was 30 and the minimum score that a respondent could obtain was zero. The questions covered full range of water management practices from discharge of water from reservoir to application of water to the farmer's field. The summation of scores of the correct answers for a particular respondent indicates his knowledge level about water management practices. The respondents were grouped into three categories using mean and standard deviation as measure of check.

$\begin{array}{ll}\text { Category } & \text { Range } \\ \text { Low } & \text { Less than (mean }-0.425 \mathrm{SD}) \\ \text { Medium } & \text { In between }(\text { mean } \pm 0.425 \mathrm{SD}) \\ \text { High } & \text { More than }(\text { mean }+0.425 \mathrm{SD})\end{array}$

The data thus collected for the purpose of the study were quantified, categorized and tabulated. The Karl Pearson's product movement correlation coefficient, Percentage, Mean and Standard deviation analytical tools and techniques have been adopted in the study to analyse the data.

\section{RESULTS AND DISCUSSION}

Overall knowledge of the farmers about selected water management practices in command area: The result of overall knowledge of the farmers about selected water management practices in command area is presented in Table 1 revealed that, 51.67 per cent of the farmers had high knowledge level about water management practices, followed by medium $(30.00 \%)$ and low $(18.33 \%)$.

The probable reason might be that, the farmers were experienced both the situations of irrigation water viz., ample of water and scarcity of irrigation water. These situations might have taught them how to manage the water in both the situation by various water management practices. With their high farming experience, the farmers learnt many waters management practices for judicious use of irrigation water. Hence, this might be the reason for high knowledge level of the farmers with respect to water management. The finding is contrast with the findings of Prajapati (2013). 
Table 1. Distribution of the farmers according to their overall knowledge about selected water management practices in command area $(\mathrm{N}=\mathbf{2 4 0})$

\begin{tabular}{llll}
\hline Categories & Range & No. & $\%$ \\
\hline Low (Mean-0.425*SD) & $<10.36$ & 44 & 18.33 \\
Medium & $10.37-12.50$ & 72 & 30.00 \\
$($ Between mean $\pm 0.425 * \mathrm{SD})$ & & & \\
High (Mean+0.425*SD) & $>12.51$ & 124 & 51.67 \\
& Mean=14.61 & SD $=5.71$ \\
\hline
\end{tabular}

Knowledge of the farmers about maintenance of channels and distributaries: A perusal of knowledge of the farmers about maintenance of channels and distributaries was recorded in Table 2 depicts that, among various practices cent per cent of the farmers had knowledge about clean maintenance of water channels from weeds, plants, stones and other agricultural wastes for its effective performance.

It was significant observation to note that, large majority $(88.75 \%)$ of the farmers had knowledge about maintenance of field channels results to adequate availability of water to all farmers, followed by lining of the channels is essential to reduce the seepage losses (82.08\%), field channel outlet planned above the ground level for easy supply of water to the farmers land $(80.42 \%)$, desilting of channels is a practice of removal of silt from the channels $(77.50 \%)$ and maintenance of shorter length of field channels (less than $1 \mathrm{~km}$ ) leads to effective water management (66.67\%), respectively.

The reason behind this result might be that, the extension activities were undertaken by the CADA and even line departments, they impart the training to the farmers regarding the water and soil management practices. In canal source of irrigation there reaching equitable water to the ultimate users is the main aim, to attain this aim the regular monitoring the channels by removing the weeds, plants, stones, silt and other agricultural wastes from the channels are required. The lining the channels by impervious materials to avoid seepage and infiltration losses. These are inevitably known by the farmers. The engineering wing of the CADA department could plan and execute the channels, distributaries and field irrigation channels, these should be planned little above the ground level for easy supply of water to the farmer's field. The eroded soil from the field would settle in the channels or other water supply systems, which restrict the movement of the water. There regular monitoring and cleaning of the silt is very important. The channels should not be too long (more than $1 \mathrm{~km}$ ) which results to conveyance loss.

Knowledge of the farmers about methods of irrigation: With respect to knowledge of the farmers about methods of irrigation, the data presented in Table 2 shows that, cent per cent of the farmers had knowledge about warabandi system of irrigation is a rotational method for equitable distribution of water, followed by crop must irrigate at it's critical crop stages $(92.08 \%)$, alternate furrow irrigation can manage soil moisture and increase water use efficiency (86.25\%), use of micro-irrigation technique is an efficient water management practice $(82.08 \%)$, morning or evening time is the best to irrigate the crops for efficient management of water $(68.75 \%)$ and topography of land determines the selection of irrigation methods $(63.75 \%)$, respectively.

The fact for the result might be that, beneficiary farmers in the command area were receive the water by warabandi method, with their exhaustive experience in farming the farmer were aware of the essentiality of water for irrigation. The warabandi system of distribution was water facilitates the equitable distribution of water to all and helps all the farmers to get water. As in command area warabandi system of irrigation is mandatory, therefore all the farmers know the system. Irrigating the crops at their critical crops stages results to water saving and can extend the area of irrigation and can prevent the water logging. This was known by the farmers, because they receive water by warabandi system and they experienced scarcity of water. With the vast experience of the farmers, they know that, alternate furrow irrigation method can save water and this method helps during water scarcity situation to withstand the crops. The installation of micro-irrigation techniques helps for efficient use of water. The government schemes and private company's demonstration regarding the usage of micro-irrigation techniques. The farmers had knowledge about microirrigation. Most of the farmers were knows that, during afternoon due to high temperature the irrigated water gets loss by evaporation before uptake by the plants. The topography of land and soil determines the selection of method of irrigation. Most the farmers had high experience in farming lead to the knowledge about these practices.

Knowledge of the farmers about water saving techniques: Regarding knowledge of the farmers about 
Table 2. Distribution of the farmers based on knowledge about selected water management practices in command area $(N=240)$

\begin{tabular}{|c|c|c|}
\hline Water management practices & No. & $\%$ \\
\hline \multicolumn{3}{|l|}{ Maintenance of channels and distributaries } \\
\hline Water channels are to be kept clean from weeds, plants, stones and other agricultural wastes & 240 & 100.00 \\
\hline Lining of the channels is essential to reduce the seepage losses & 197 & 82.08 \\
\hline The maintenance of shorter length of field channels (less than $1 \mathrm{~km}$ ) leads to effective water management & 160 & 66.67 \\
\hline Maintenance of field channels results to adequate availability of water to all farmers & 213 & 88.75 \\
\hline Field channel outlet planned above the ground level for easy supply of water to the farmers land & 193 & 80.42 \\
\hline Desilting of channels is a practice of removal of silt from the channels & 186 & 77.50 \\
\hline \multicolumn{3}{|l|}{ Methods of irrigation } \\
\hline Morning or evening time is the best to irrigate the crops for efficient management of water & 165 & 68.75 \\
\hline Alternate furrow irrigation can manage soil moisture and increase water use efficiency & 207 & 86.25 \\
\hline Warabandi system of irrigation is a rotational method for equitable distribution of water & 240 & 100.00 \\
\hline Use of micro-irrigation technique is an efficient water management practice & 197 & 82.08 \\
\hline Topography of land determines the selection of irrigation methods & 153 & 63.75 \\
\hline Crop must irrigate at it's critical crop stages & 221 & 92.08 \\
\hline \multicolumn{3}{|l|}{ Water saving techniques } \\
\hline Soil mulching can reduces evaporation loss & 139 & 57.92 \\
\hline Conservation tillage can save water by reducing evaporation loss & 163 & 67.92 \\
\hline Growing of different root system crops enables for effective utilization of water & 91 & 37.92 \\
\hline Land levelling facilitates for effective water management & 220 & 91.67 \\
\hline Planned schedule of irrigation can save water and maximizes yield & 208 & 86.67 \\
\hline Application of FYM and compost helps to increase water holding capacity of the soil & 173 & 72.08 \\
\hline \multicolumn{3}{|l|}{ Selection of crops and its cultivation practices } \\
\hline Growing of short duration varieties or hybrids to overcome water stress & 153 & 63.75 \\
\hline Wider spacing and optimum plant population facilitates the regular supply of moisture thought the year & 198 & 82.50 \\
\hline Drought tolerant varieties are preferred in water scarcity situation & 115 & 47.91 \\
\hline Growing less water consuming crops to extend the irrigated land and can save water for succeeding crops & 141 & 58.75 \\
\hline Intercultural operations viz., hoeing, harrowing etc., can conserve soil moisture by closing cracks in the soil & 240 & 100.00 \\
\hline Decide cropping pattern based on availability of the irrigation water & 216 & 90.00 \\
\hline Summer ploughing conserve water by reducing runoff & 197 & 82.08 \\
\hline \multicolumn{3}{|l|}{ Excess water management techniques } \\
\hline Surface/sub surface drainages enables to overcome the problem of waterlogging and salinity in the command areas & 181 & 75.42 \\
\hline Probability of receiving irrigation water is high than prefer broad bed furrows & 83 & 34.58 \\
\hline Storage of excess water in farm pond or dugout structure for effective management of excess water & 148 & 61.67 \\
\hline Regular monitoring of drainage system facilitates for flowing of excess water uninterruptedly & 221 & 92.08 \\
\hline Formation of bunding along the borders of the field facilitates to conserve soil and excess water & 201 & 83.75 \\
\hline
\end{tabular}

water saving techniques, it could be observed from the Table 2 that, majority $(91.67 \%)$ of the farmers had knowledge about land levelling facilitates for effective water management. While, 86.67 per cent of the farmers had knowledge regarding planned schedule of irrigation can save water and maximizes yield, followed by application of FYM and compost helps to increase water holding capacity of the soil $(72.08 \%)$, conservation tillage can save water by reducing evaporation loss
(67.92\%), soil mulching can reduce evaporation loss $(57.92 \%)$ and growing of different root system crops enables for effective utilization of water $(37.92 \%)$, respectively.

The probable reason might be that, the undulated land leads to difficulty and uneven distribution of irrigation water. The land levelling is the pre-requisite practice in canal irrigation, if the land was levelled in a proper slope result to uninterrupted distribution of water to all the 
farmers. The regular involvement of farmers in various farming activities made them when to irrigate, how to irrigate and how much to irrigate. Therefore, the farmers might plan the scheduling of irrigation for effective usage of water. The age-old farmers were more concentrate towards the application of FYM to the field, they knew that, the FYM can increase the microbial activities of the soil as well as improve the water holding capacity of the soil. As the farmers were practicing many intercultural operations in the field might learnt that, the conservation and zero tillage can save water by reducing evaporation loss. Most of the farmers were not practicing the soil mulching and most of the farmers were grow the crops of regular practice. Hence, they don't have much knowledge about how to prefer different rooted crops for judicious usage of available water.

Knowledge of the farmers about selection of crops and its cultivation practices: With respect to knowledge of the farmers about selection of crops and its cultivation practices, it could be noticed from the Table 2 that, cent per cent of the farmers had knowledge about intercultural operations viz., hoeing, harrowing etc., can conserve soil moisture by closing cracks in the soil. Whereas, 90.00 per cent of the farmers had knowledge about deciding cropping pattern based on availability of the irrigation water, followed by wider spacing and optimum plant population facilitates the regular supply of moisture thought the year $(82.50 \%)$, summer ploughing conserve water by reducing runoff $(82.08 \%)$, growing of short duration varieties or hybrids to overcome water stress $(63.75 \%)$, growing less water consuming crops to extend the irrigated land and can save water for succeeding crops $(58.75 \%)$ and drought tolerant varieties are preferred in water scarcity situation (47.91\%), respectively.

The reason behind this result might be that, the intercultural operations were perform to enrich the soil property in terms of retaining soil moisture by reducing evaporation loss and removing the weeds to reduce competition of water with the main crops. The availability of irrigation water in command area depends on the rainfall of that year, there is no assurance that the farmers would get water. Hence, based on the availability of water they plan the cropping pattern, spacing and plant population. Once the harvest of the crop from the field the farmers were allow the land to expose to the solar radiations and during summer, they plough the lands for proper aeration results to reduce the runoff of rain water and increase the soil moisture level. During water scarcity situation, the farmers had to prefer the short duration, less water consuming and drought tolerant crops.

Knowledge of the farmers about excess water management techniques: A perusal of knowledge of the farmers about excess water management techniques recorded in Table 2 depicts that, majority (92.08\%) of the farmers had knowledge about regular monitoring of drainage system facilitates for flowing of excess water uninterruptedly, followed by formation of bunding along the borders of the field facilitates to conserve soil and excess water $(83.75 \%)$, surface/sub surface drainages enable to overcome the problem of waterlogging and salinity in the command area (75.42\%), storage of excess water in farm pond or dugout structure for effective management of excess water $(61.67 \%)$ and probability of receiving irrigation water is high than prefer broad bed furrows (34.58\%), respectively.

The reason might be that, the farmers were beneficiaries of the canal water they might aware that, sometimes they could get excess water that leads to water logging and salinity of the soil. Hence, they had much knowledge about the construction and proper monitoring of the drainage systems. The bunding at the borders of the field can conserve the soil and water by runoff. The surface and sub-surface drainages will remove the excess water from the field and prevents the crops from wilting and dieback. Even the excess water might store in the ponds or other dugout structure to use in water scarce situations.

Relationship between selected independent variables and knowledge level of the farmers: The correlation coefficient of the personal, socio-economic and psychological variables with knowledge level of the farmers about water management practices has been presented in Table 3.

It could be seen from Table 3 that, among 14 selected independent variables, three variables viz., age, farming experience and extension contact had exhibited positive and significant relationship at one per cent level of probability. Five variable such as, extension participation, mass media utilization, scientific orientation, achievement motivation and innovativeness had exhibited positive and significant relationship at five per cent level of probability. Remaining six variables viz., 
education, size of land holding, family type, annual income, risk orientation and management orientation did not exhibit any significant relationship with knowledge level of the farmers.

Table 3. Relationship between selected independent variables with knowledge of the farmers about water management practices in command area $(\mathrm{N}=\mathbf{2 4 0})$

\begin{tabular}{ll}
\hline Independent variables & $(\mathrm{r})$ \\
\hline Age & $0.334^{* *}$ \\
Education & $0.102^{\mathrm{NS}}$ \\
Size of land holding & $0.092^{\mathrm{NS}}$ \\
Farming experience & $0.387^{* *}$ \\
Family type & $0.021^{\mathrm{NS}}$ \\
Annual income & $0.072^{\mathrm{NS}}$ \\
Extension contact & $0.312^{* *}$ \\
Extension participation & $0.253^{*}$ \\
Mass media utilization & $0.161^{*}$ \\
Scientific orientation & $0.221^{*}$ \\
Risk orientation & $0.014^{\mathrm{NS}}$ \\
Management orientation & $0.078^{\mathrm{NS}}$ \\
Achievement motivation & $0.199^{*}$ \\
Innovativeness & $0.191^{*}$ \\
\hline
\end{tabular}

$*=$ Significant at $5 \% \quad * *=$ Significant at $1 \%$ $\mathrm{NS}=$ Non-significant

The possible reason might be that, majority of the farmers were belonged to medium to old age category and have higher farming experience, because of which they had high knowledge about water management practices. As the line departments conduct the extension activities and the farmers were participated in the activities. The scientific orientation was medium to high, as the department were regularly provide the scientific updates to the farmers. The farmers were faced the constraints of irrigation before implementation of UKP project and the farmers were receiving the water because of this project and they realized the importance of irrigation and its management in farming. Therefore, they had strong motive to achieve something in farming and they were gathering the knowledge from various sources. Even the innovativeness leads to new experience and increases the knowledge of the farmers. Hence, all these variables were positive and significantly related with the knowledge of the farmers.

\section{CONCLUSION}

The Northern Karnataka region farmers had faced the problem of water to irrigate the crops as water is a basic entity for crop production. With the intervention of Upper Krishna Command area in North Karnataka region had drastically changed the farming situation and improved their socio-economic condition. The Command Area Development Authority (CADA) had initiated various farmer's development activities with respect to water management. Hence, the farmers had relatively high knowledge about water management in command area.

\section{CONFLICTS OF INTEREST}

The authors declare that they have no conflicts of interest.

\section{REFERENCES}

Anonymous, (1996). Planning and management of Upper Krishna Project - Situational analysis. Irrigation Department, Government of Karnataka. pp 138-142.

Chinnadurai, M.; Paramasivam, P.; Swaminathan, B. and Dharuman, V. (2013). Evaluation study of the command area development and water management programme in Gundar, Chittar and Karuppanadhi project. Tamil Nadu Agric. Univ. Coimbatore (India).

Prajapati, V.V. and Patel, B. K. (2013). Constraints faced by the beneficiary farmers in adoption of watershed crop production technology. AGRES - An Int. e-J. 2 (2): 240-245.

Sashilila, A.O. and Patra, N. K. (2018). Performance of integrated watershed management programme (IWMP) in social inclusion in Wokha district of Nagaland, India. Indian Res. J. Ext. Edu., 18 (3) : 38-43.

Shaik, M.S.R. and Khandave, S. (2019). Socio economic impact of drip irrigation system on drip owners. Indian Res. J. Ext. Edu., 19 (4):92-95. 